\title{
Back to nature: herbal treatment, environmental enrichment, and social play can protect against unpredictable chronic stress in Long-Evans rats (Rattus norvegicus)
}

\author{
Kiana Nwachukwu ${ }^{1}$ Elizabeth Rhoads ${ }^{1} \cdot$ Sarah Meek $^{1} \cdot$ Massimo Bardi $^{1,2} \mathbb{D}$ \\ Received: 4 March 2021 / Accepted: 30 June 2021 / Published online: 1 August 2021 \\ (c) The Author(s), under exclusive licence to Springer-Verlag GmbH Germany, part of Springer Nature 2021
}

\begin{abstract}
The importance of integrative biobehavioral responses to complex challenges cannot be overlooked. In this study, the synergetic effects of icariin (a flavonoid present in the plant Epimedium brevicornum), natural enrichment (NaEn), and play behavior were investigated. Rats $(n=60)$ were assigned to standard housing or $\mathrm{NaEn}$; these two groups were subsequently divided into controls, rats receiving icariin treatments, and rats receiving icariin and allowed to play with an individual from another cage. All rats were exposed to unpredictable mild stressors for 4 weeks. At the end of the treatment, a Forced Swim Task (FST) was conducted to assess emotional regulation during an inescapable acute challenge. Biological samples were collected weekly and before and after the FST to monitor endocrine changes. Corticosterone (CORT), dehydroepiandrosterone (DHEA), and testosterone (T) were assayed. We found that icariin had a significant effect on DHEA/CORT ratios and T levels. NaEn also had a significant effect on both CORT and DHEA, but not on T levels. Play did not appear to be significantly related to the endocrine changes. The strongest positive effects on emotional resilience were observed in NaEn rats that also received icariin. Our results confirmed that using multiple channels to stimulate adaptive responses can be effective in increasing the ability of an organism to face uncertainty. Considering how quickly our life can change due to unpredictable events, our data is instrumental to a better comprehension of the many aspects of integrative biobehavioral responses.
\end{abstract}

Keywords Icariin $\cdot$ Natural enrichment $\cdot$ Play $\cdot$ Stress $\cdot$ Steroid hormones

\section{Introduction}

Humans pay a very hefty toll due to the consequences of chronic unpredictable stress: affective disorder rates related to high stress remain high despite the use of prescribed medication, which has increased nearly threefold from the early 2000 s to reach an astonishing $21.8 \%$ reported in a recent national survey (Maust et al., 2017). On the other hand, psychotherapy and other behavioral and/or natural remedies have been experiencing a reverse trend, with patients' use of these methods decreasing from about $30 \%$ in the late 1990s to less than 20\% (Olfson and Marcus, 2009). This is

Massimo Bardi

massimobardi@rmc.edu

1 Department of Psychology and Neuroscience, RandolphMacon College, Ashland, VA 23005, USA

2 134D Copley Science Center, Randolph-Macon College, Ashland, VA 23005, USA problematic for two main reasons: (1) we do not fully understand the wide range of behavioral and neurological side effects of psychoactive drugs (Cascade et al., 2009; Lakhan and Vieira, 2010; Lee et al., 2016); and (2) we do not have a clear picture of the effectiveness of the drugs currently used; in fact, several studies revealed that placebo effects can often mask, if not completely surpass, the therapeutic effects of the drug (Enck et al., 2008; Benedetti et al., 2011). Emotional resilience can act as a neurobiological buffer against the negative effects of stress and can consequently lead to decreased susceptibility to psychiatric illnesses, which can lower the probability of a dangerous spiral toward overconsumption of antidepressant and sedative drugs (Lambert et al., 2014). Therefore, we should prioritize more studies on how to naturally increase emotional resilience and an organism's ability to respond to stressful situations in an adaptive manner.

Natural enhancers of emotional resilience have been studied extensively (Kinrys et al., 2009; Lakhan and Vieira, 2010). Recently, compelling evidence has emerged on the 
positive effects of icariin, the most common constituent of flavonoids isolated from Epimedium brevicornum (Li et al., 2015; He et al., 2020). This plant belongs to the Berberidaceae family and is endemic to China and the Mediterranean region (Ma et al., 2011). In China, alternative medicine has been institutionalized and employed alongside western medicine for physician-monitored treatments including symptom relief, increased quality of life, and immune response improvement (McQuade et al., 2012). Icariin can exercise a protective effect against corticosterone provoked apoptosis in the hippocampus, as well as generally improve the function of the cardiovascular system specifically under mild oxygen deprivation (Liu et, al. 2015; Sun et al., 2019). Studies have also shown that icariin can be used to reduce the degenerative effects after a stroke (Pan et al., 2007). Central mechanisms of activations for icariin have been recently identified, including a significant increase in sucrose intake, which could be related to a more efficient metabolic function, and an upregulation of neuroprotective factors in the hippocampus, such as brain-derived neurotrophic factors (BDNF) and Neuropeptide-Y (NPY) (Pan et al., 2013; Gong et al., 2016). More specifically to the current study, icariin has been shown to enhance neuroprotective mechanisms against stressful events (Hritcu et al., 2017). For example, a study published in 2016 found that icariin can reduce depression-like behavior in rats exposed to mild chronic stress by downregulating the mRNA expression of glucocorticoid receptors in the hippocampus (Wei et al., 2016).

Pharmacokinetically, icariin is widely distributed in the body, including the brain, indicating that icariin can bypass the blood-brain barrier (Li and Wang, 2008). Metabolic and pharmacokinetic studies have shown that these icariin derivatives, such as icariside I, icariside II, and desmethylicaritin, can be found in the intestine through deactivation by intestinal flora (Xu et al., 2007). Pharmacological studies have also found that icariin is a prenylated flavonol glycoside with rhamnosyl, glucosyl, and methoxy groups. Deglycosylation or demethylation of icariin can form different metabolites. For instance, icariside I is formed when the rhamnose residue is removed, whereas icariside II is formed when the glucose residue is removed (Khan et al. 2015).

Social and physical environments can have profound effects on how the endocrine system mediates the response to external threats (Tafet and Nemeroff, 2016). For example, raising rats in an enriched environment can decrease stress, improve neuroplasticity, and reduce inflamm-aging (Vega-Rivera et al., 2016; Ashokan et al., 2018; Scarola and Bardi, 2020). In our laboratory, we went a step further to provide evidence that natural enrichment (NaEn) can be even more effective than artificial enrichment (Bardi et al., 2016; Lambert et al., 2016; Scarola et al., 2019). We found that $\mathrm{NaEn}$ promoted not only environmental exploration, but social interactions as well; the promotion of these behaviors had a variety of positive effects on rats, such as reducing anxiety-like behaviors and increasing emotional resilience (Bardi et al., 2016; Lambert et al., 2016). Numerous studies demonstrated that living near rural or coastal environments is beneficial for human health (Mitchell and Popham, 2008; Park et al., 2010; Rook, 2013). Additionally, it appears to reduce overall mortality and depressive symptoms, effects also related to increased subjective feelings of well-being. Clinical studies have demonstrated that patients recover more quickly when exposed to natural stimuli via mechanisms related to stress reduction and restorative influence (Ulrich, 1984; Frumkin et al., 2017). Based on these findings, it is critical to investigate the synergetic effects of herbal treatments and $\mathrm{NaEn}$.

Play behavior in mammals is an essential part of development due to its crucial role in acquiring behavioral cues and learning how to communicate with others (Pellis et al., 2010; Vanderschuren et al., 2016). Recent studies have found an intriguing connection between social play and the animal's ability to process another animal's emotional state - a condition often referred to as empathy; pain contagion is common when they are relaxed, but when animals are in a state of stress, they tend to disregard signs of pain in other individuals (Martin et al., 2015). Interestingly, individuals have also shown increased stress when deprived of play (Pellis and Pellis, 2007). Evidence also showed that environmental enrichment is directly linked to higher frequencies of social play and, consequently, stress reduction (Nithianantharajah and Hannan, 2006; Bardi et al., 2016).

Early life experiences can exercise long-lasting effects influencing brain function, behavior, and emotional regulation (McEwen, 2008). It is well known that early life adversity can increase the risk for several systemic and mental disorders in both humans (Fagundes et al., 2013; Rehan et al., 2017) and non-human animals (Dallman et al. 1994). In our laboratory, we showed that early exposure to enriched conditions and positive training can have effects spanning the entire life of rats (Scarola and Bardi, 2020) and have profound consequences for emotional regulation and cognitive development (Bardi et al., 2012, 2013; 2016; Scarola et al., 2020). Therefore, adolescent rats were selected in this experiment.

To monitor physiological stress, biomarkers of the hypothalamic-pituitary-adrenal (HPA) and the hypothalamic-pituitary-gonadal (HPG) axes were measured with non-invasive methods. Corticosterone (CORT) and dehydroepiandrosterone (DHEA) were assessed in parallel to differentiate between the positive and negative effects of HPA activation (Scarola et al., 2019). DHEA is released during a stress response to inhibit both catecholamine upregulation in the adrenal medulla, as well as many of the negative effects of glucocorticoids in various tissues (Charney, 2004). Potentially related to the reduction in stress response 
and anxiety-like behaviors, research has demonstrated that DHEA can act centrally to decrease glucocorticoid-induced neuronal death in the hippocampus, in addition to promoting neurogenesis in the dentate gyrus of the hippocampus and in the sensory dorsal root ganglion neurons (Morgan et al., 2009). Furthermore, the ratio between DHEA and CORT has been found to be a reliable index of neuroprotection and has a positive association with exposure to both $\mathrm{NaEn}$ and social interactions (Maninger et al., 2009; Bardi et al., 2016; Lambert et al., 2016). Little is known about the potential role of DHEA and icariin; however, it is known that icariin can act as a testosterone enhancer in male rats (Zhang and Yang, 2006). Testosterone ( $\mathrm{T}$ ) plays a crucial role in behavioral modifications related to the reproductive effort of males, and it is well known that in response to stress, the peripheral concentrations of $\mathrm{T}$ often decrease (Charmandari et al., 2005).

The main goal of the present study was to investigate the synergetic effects of icariin, $\mathrm{NaEn}$, and social play on Long-Evans male rats exposed to unpredictable chronic stress. Rats were exposed to ecologically relevant stressors for 4 weeks. Immediately following the treatment period, rats were challenged with a Forced Swim Task (FST). HPA and HPG activity were assessed weekly during the exposure to chronic stress. Pre- and post-FST biomarkers levels were also measured. We hypothesized that any of the three natural treatments (icariin administration; NaEn; and social play) would ameliorate the rats' response to chronic stress by increasing DHEA/CORT ratios and T levels. We also hypothesized that the strength of these effects would be increased when rats were exposed to multiple treatments, thus demonstrating a synergetic interaction among them. Considering the pressing need to find safe natural treatments for skyrocketing stress levels in humans, our results could be useful for future translational research on improving emotional resilience.

\section{Materials and methods}

\section{Ethics statement}

Rats were maintained in accordance with the RandolphMacon College Institutional Animal Care and Use Committee (protocol no. 19-01).

\section{Rats, housing, and procedures}

We purchased sixty male Long-Evans rats (Rattus norvegicus), about 23 days old, from Envigo (Indianapolis, IN, USA). We focused on males to avoid further complications due to sex differences. Future studies will focus on females to obtain a more complete picture of the sex differences. Rats were selected at a prepubertal age to include this critical phase of their development, although this selection could introduce another confounding variable, differences in sexual maturation. When they arrived in our laboratory, rats weighed approximately $35-45 \mathrm{~g}$, and they were all pathogen free. The sixty rats were paired randomly and placed in standard housing $(48 \mathrm{~cm} \mathrm{~L} \times 26 \mathrm{~cm} \mathrm{~W} \times 21 \mathrm{~cm}$ $\mathrm{H}$ cages with approximately 2 inches of corn cob bedding) for 6 days prior to treatments to be habituated to the environment. Corncob bedding and rodent chow were also acquired from Envigo (catalog no. T.2018.15, Teklad Global 18\% Protein Rodent Diet, Envigo, Indianapolis, IN). Water was available ad libitum. Rats were on a 12-h light-dark cycle, with lights on at $0800 \mathrm{~h}$ and off at $2000 \mathrm{~h}$. Although light was kept constant in all rooms throughout the experiment, we do not have a precise measurement of light intensity in Lux, and thus slightly variations in light exposure could be another confounding variable in this study.

After habitation, rats were randomly assigned to standard housing or naturally enriched ( $\mathrm{NaEn}$ ) housing for the remainder of the experiment (4 weeks). These two groups were subsequently divided into controls (Control Standard housing (CS), $n=10$; Control Enriched housing (CE), $n=10$ ), rats receiving icariin treatments (Icarin Standard housing (IS), $n=10$; Icarin Enriched housing (IE), $n=10$ ), and rats receiving icariin and allowed to play with an individual from another cage for $5 \mathrm{~min}$ (pairs were the same throughout the study) (Icariin Play Standard housing (IPS), $n=10$; Icariin Play Enriched housing (IPE), $n=10)$ (Fig.1A).

Enriched housing consisted of natural objects (one large wooden stick to promote climbing, 3-4 stones, one small piece of wood, one handful of aspen bedding, and one natural hideaway) and twice as much corn cob bedding (Fig. 1B).

All rats were exposed to unpredictable mild stressors for the 4 weeks of treatment. To simulate ecologically valid stressors, rats were exposed to randomly selected stressors every other day. Three kinds of stressors were selected: (1) Predator-odor stressor: red fox urine (100 $\mu \mathrm{L}$; acquired from Pete Rickard Co., Cobleskill, NY) was injected into a cotton ball placed in the corner of an empty cage for $10 \mathrm{~min}$; (2) Predator-sound stressor: hawk and owl calls were played over speakers (HK206, Computer Speakers, Harmon Kardon, Stamford, CT) at moderate volume for $10 \mathrm{~min}$; (3) Predator-touch stressor: a large binder clip was applied to the tip of the tail for 5 min to simulate tail pinching from a predator. Although all three the above challenges are rough simulation of real-life events, all three have been validated as enhancing stress in a way to approximate ecological challenges. 


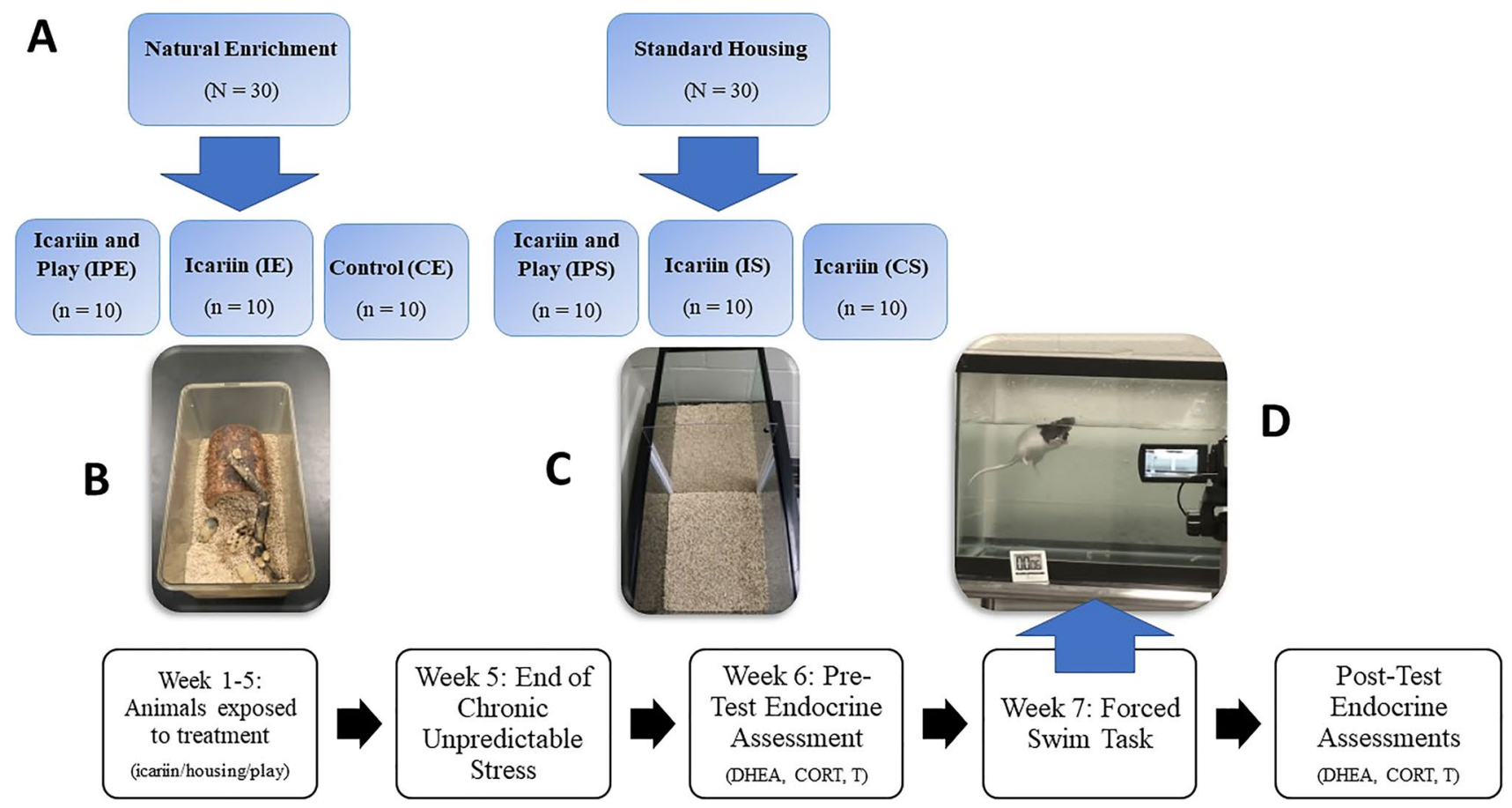

Fig. 1 Timeline and apparatus. A Detail of the six experimental groups. B Example of a naturally enriched cage. C The play area with the transparent divider. D Apparatus for the Forced Swim Task

\section{Herbal treatment}

We purchased $7 \mathrm{~g}$ of icariin from Tokyo Chemical Industry Co., Ltd (Nihonbashi-honcho, Chuo-ku, Tokyo) analyzed by the manufacturer's high-performance liquid chromatography (HPLC) which indicated a purity of $96 \%$. Eagle Brand sweetened condensed milk was mixed 1:1 with deionized water as the saline solution. The optimal dose of icariin, as determined by a pilot study conducted in our laboratory with low and high doses as treatment for chronic stress in Long-Evans rats (Johnson, 2019), was obtained by dissolving $80 \mathrm{mg} / \mathrm{kg}$ in $40 \mathrm{~mL}$ of saline solution. This pilot study was conducted prior of the experiments on a different cohort of 29 male rats of similar age and housed in similar conditions. The low dose (LD) was selected at $40 \mathrm{mg} / \mathrm{kg}(n=10)$ and high dose (HD) was double that amount, $80 \mathrm{mg} / \mathrm{kg}(n=10)$. These dosages were selected from the literature (Liu et al., 2015). Icariin was given twice per week for 4 weeks. The control group $(n=9)$ received $0.2 \mathrm{mg}$ of $5 \mathrm{~mL}$ condensed milk mixed with $5 \mathrm{~mL}$ of water (414.08 micromolar). The weight of each rat was taken each week and all drugs were administered at $1700 \mathrm{~h}$ to minimize interactions between circadian rhythm and environmental factors. Following the administration of the drug, rats were monitored for abnormal behaviors in their original housing conditions.
Results indicated that both cortisol and DHEA level changed significantly at HD, but not at LD (cortisol: $F(2,26)=17.821, p<0.001$; DHEA: $F(2,26)=25.351$, $p<0.001)$. This is why in the current study we focused only on HD.

The saline group received a dose equaling the average amount of icariin doses for each week based on weight. Icariin and saline were administered following unpredictable stress treatments Monday, Wednesday, and Friday for 4 weeks.

\section{Novel social play interaction}

Social play behavior with an unfamiliar male was observed in 20 rats. Rats were housed in pairs and therefore they had unmonitored social interactions with their cage mate. To assess the benefits of novel social play interactions, individual rats were paired with an unfamiliar rat from another cage for the duration of the experiment. The play behavior occurred in a room separated from housing. The play arena was constituted by a tank $(76 \mathrm{~cm} \mathrm{~L} \times 31 \mathrm{~cm} \mathrm{~W} \times 32 \mathrm{~cm} \mathrm{H})$ that contained corncob bedding and a transparent divider (Fig. 1C). Rats were habituated in pairs individually for $10 \mathrm{~min}$ before starting the social treatment exposure. Five days a week, rats were brought to the play arena in the afternoon between 1300 and $1500 \mathrm{~h}$ for $10 \mathrm{~min}$ total. The divider 
was kept down for the first 5 min to prevent interaction; the remaining $5 \mathrm{~min}$ the divider was removed so that the rats could interact with each other.

\section{Behavioral test}

At the end of the 4 weeks of treatment, a Forced Swim Task (FST) was conducted to assess emotional regulation during an inescapable challenge, as described in previous works (Bardi et al., 2012). Briefly, rats were individually placed in a tank $(62 \mathrm{~cm} \mathrm{~L} \times 32 \mathrm{~cm} \mathrm{~W} \times 53 \mathrm{~cm} \mathrm{H})$ filled with $21{ }^{\circ} \mathrm{C}$ water and allotted $3 \mathrm{~min}$ to swim to stimulate an acute challenge (Fig. 1D). Behavioral responses were measured to verify that the task was challenging for the rats. Rats were monitored for the frequencies of dives and shakes. Dives were defined as a motion toward the bottom of the tank with the head completely submerged. As shown in previous works (Bardi et al., 2016; Lambert et al., 2016), dives are an indication of the animal's ability to try to find a way out of a helpless situation. Shakes were defined as rapid rotating movements of the head and neck areas. Additionally, duration spent floating and swimming was observed. Following the completion of the trial, all rats were dried off and put back into their assigned cage. All trials were conducted on the same day between 1800 and $2300 \mathrm{~h}$.

\section{Biological sampling and hormone assays}

A baseline fresh fecal sample was collected prior to the commencement of treatments after habituation. Fresh fecal samples were collected weekly, at the end of the week, for the duration of the treatment. Samples were also collected before and after the FST to monitor the stress response of the rats to an acute challenge. Overall, samples were collected at 7 points in time.

Stored fecal samples were thawed at room temperature to prepare for extraction. Samples were subsequently placed in individual glass tubes with $1 \mathrm{~mL}$ of $100 \%$ methanol $(\mathrm{MeOH})$ and mixed via vortex (Vortex Genie 2, Scientific Industries, Inc.) for approximately $30 \mathrm{~s}$. Following mixing, the tubes were centrifuged for $15 \mathrm{~min}$ at $3000 \times \mathrm{g}$. The samples were then transferred to new test tubes using a transfer pipette. Samples were then diluted in $\mathrm{MeOH}$ (concentration 1:20) in an EIA buffer. Assay was completed by utilizing the materials and protocols provided by an Enzyme-Linked Immuno-Sorbent Assay (ELISA) kit (Enzo Life Science, Farmingdale, NY, USA). Sample readings were conducted using an automated micro-plate reader (BioTek, Winooski, VT, model Synergy) with the Gen5 software (BioTek, Winooski, VT, version 2.04.11). A wavelength of $405 \lambda$ with correction at $490 \lambda$ was used for the sample readings. Loglogit transformations of the data were analyzed using leastsquared regression analysis. Accuracy was verified at each standard curve point. Accuracy was demonstrated at each standard curve point $(n=8)$ : accuracy was $95.6 \pm 3.1 \%$ for CORT, $99.2 \pm 1.1 \%$ for DHEA, and $90.5 \pm 6.0 \%$ for T. Quality control pools were assayed in triplicate on each plate, with the following results: CORT (high) $6.4 \%$ coefficients of variation (cv); CORT (low) 6.9\% cv; DHEA (high) 6.0\% $c v$; DHEA (low) $5.9 \% c v$; T (high) $9.3 \% c v$; T (low) $7.8 \% c v$.

The samples were validated using previously described procedures (Scarola et al., 2019). Readings were performed using an automated microplate reader (BioTek, Winooski, VT, model Synergy) and Gen5 software (BioTek, Winooski, VT, version 2.04.11). Readings were analyzed at a wavelength of $405 \lambda$ with correction at $490 \lambda$.

Assays were validated using standard methods described in previous research in our laboratory (Bardi et al. 2010).

\section{Statistical analysis}

General linear models (GLM) were used to determine the changes in HPA and HPG activity across the treatments and before and after the FST. Factors entered in the models (independent variables) were icariin administration (icariin/ saline), exposure to the enrichment ( $\mathrm{NaEn} / \mathrm{standard}$ housing), and exposure to play with an unfamiliar individual (play/no play). To evaluate the overall, independent effects of the treatments on the endocrine profile of rats after chronic stress, and in response to an acute stressor (FST), a series of models using a stepwise discriminant analysis (DA) were run. Discriminant analysis is a cluster analysis often used to classify cases into groups on the bases of various response variables. It offers information as to which characteristics discriminate best between groups and analyzes the precision of these characteristics for group classification. Three stepwise DA were conducted on each of the treatment group (housing/icariin/play) using the following endocrine response variables: difference in hormone values between the baseline (prior to any treatment) and at the end of the chronic stress period, difference in hormone values between the pre- and post-FST. Since 3 hormones were assessed (CORT, DHEA, T), a total of 6 predictors were initially entered into each model. All analyses were performed using SPSS 25.0 (IBM, Armonk, NY).

\section{Results}

\section{Metabolized CORT levels}

Metabolized CORT levels steadily increased during the experiment $\left(F(6,354)=129.9, p<0.001, \eta^{2}=0.688\right)$. At the end of the 4 weeks of exposure to chronic stress, CORT levels were almost double than at the baseline (Fig. 2A). Before the FST task, CORT was still elevated, right after the FST, the average for all rats increased significantly, surpassing 

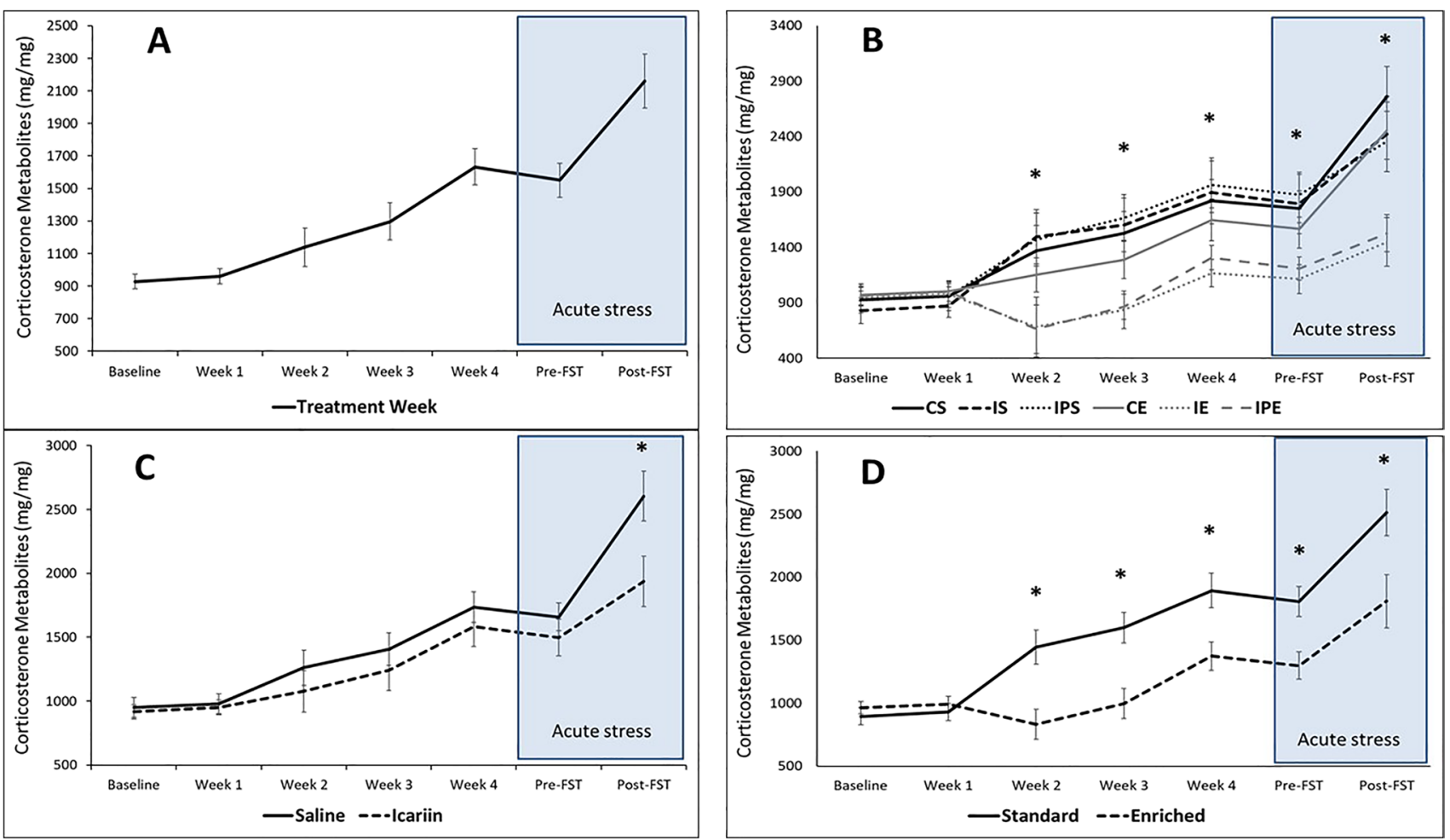

Fig. 2 Metabolized CORT levels $(\mu \mathrm{g} / \mathrm{mg} \pm 2$ SEM) during the exposure to unpredictable stress (weeks 1 through 4), and before and after the Forced Swim Task (FST). A Average CORT levels for all rats. B CORT levels by group. SS, control rats (standard housing and saline); SI, standard housing and icariin; SIP, standard housing, icariin, and

play; ES, enriched housing and saline; EI, enriched housing and icariin; EIP, enriched housing, icariin, and play. C CORT levels in rats grouped by icariin treatment $(80 \mathrm{mg} / \mathrm{kg}$ or saline). D CORT levels in rats grouped by housing ( $\mathrm{NaEn}$ or standard)

$2000 \mathrm{pg} / \mathrm{mL}$ (Fig. 2A). This demonstrated that rats were still reactive to acute stressors at the end of the chronic stress exposure.

Metabolized CORT levels were affected by the treatments $\left(F(5,54)=14.92, p<0.001, \eta^{2}=0.58\right)$. There was a significant interaction effect between time and treatment as well ( $F$ $\left.(30,324)=10.14, p<0.001, \eta^{2}=0.484\right)$. Overall, rats in the $\mathrm{NaEn}$ condition with either or both icariin and play treatments maintained a lower CORT profile throughout the experiment than any other groups, including just exposure to $\mathrm{NaEn}$ (Fig. 2B). Focusing on the individual effect of each treatment, it was found that play, when analyzed on its own, did not affect CORT levels $\left(F(1,58)=0.54, p=0.47, \eta^{2}=0.009\right)$, whereas both icariin $\left(F(1,58)=5.64, p=0.02, \eta^{2}=0.165-\right.$ Fig. 2 C $)$ and housing $\left(F(1,58)=39.7, p<0.001, \eta^{2}=0.439-\right.$ Fig. 2D $)$ were related to a significant reduction of CORT levels. CORT changes during the experiment showed a significant interaction effect with both icariin $\left(F(6,348)=7.84, p<0.001, \eta^{2}=0.138\right.$ - Fig. 2C) and housing $\left(F(6,348)=25.66, p<0.001, \eta^{2}=0.32\right.$ - Fig. 2D): icariin affected the response of the rats specifically to the FST, whereas rats maintained in enriched housing showed a much lower profile of CORT throughout the whole experiment.

\section{Metabolized DHEA levels}

Metabolized DHEA levels increased during the experiment $\left(F(6,354)=206.9, p<0.001, \eta^{2}=0.861\right)$. At the end of the 4 weeks of exposure to chronic stress, DHEA levels were more than double the baseline levels (Fig. 3A). After the FST, the average DHEA levels for all rats increased significantly (Fig. 3A), once again demonstrating the ability to manifest an adaptive stress response to the FST.

Metabolized DHEA levels were affected by the treatments $\left(F(5,54)=12.51, p<0.001, \eta^{2}=0.536\right)$. There was a significant interaction effect between time and treatment as well $\left(F(30,324)=17.57, p<0.001, \eta^{2}=0.619\right)$. After the first 2 weeks, in which no significant difference in DHEA was observed by treatment, the key conditions to increase DHEA metabolites were play an icariin. DHEA levels did not change significantly from the baseline for rats in both standard conditions and exposed to the $\mathrm{NaEn}$ when play and icariin were not present (Fig. 3B). After the FST, a spike in DHEA metabolites levels was recorded in all groups except for the SIP group (Fig. 2B). When the individual main effects of each treatment condition was assessed, it was found that, as we found for CORT, DHEA did not 

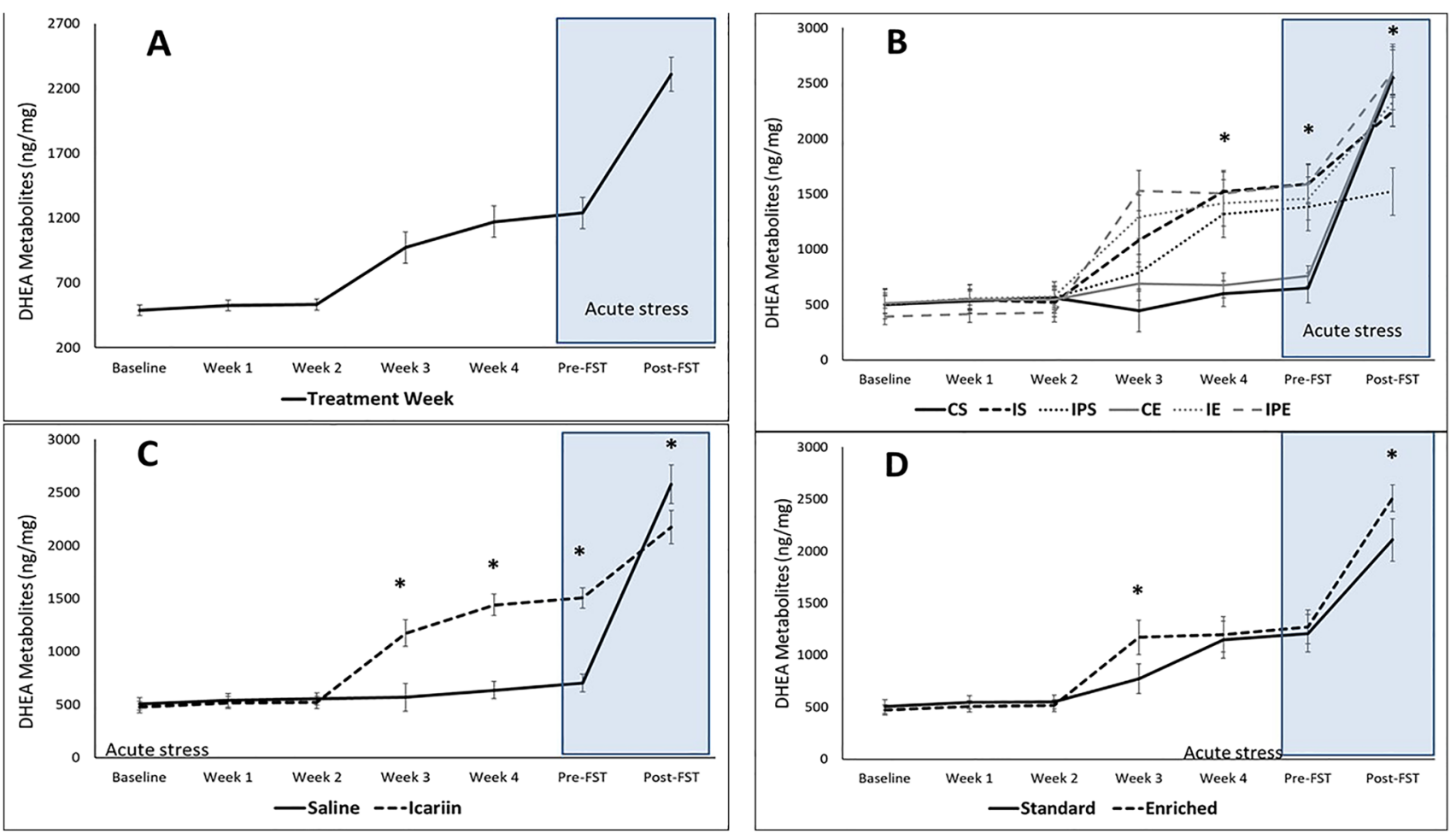

Fig. 3 Metabolized DHEA levels $(\mathrm{pg} / \mathrm{mg} \pm 2$ SEM) during the exposure to unpredictable stress (weeks 1 through 4), and before and after the Forced Swim Task (FST). A Average DHEA levels for all rats. B DHEA levels by group. SS, control rats (standard housing and saline); SI, standard housing and icariin; SIP, standard housing,

icariin, and play; ES, enriched housing and saline; EI, enriched housing and icariin; EIP, enriched housing, icariin, and play. C DHEA levels in rats grouped by icariin treatment $(80 \mathrm{mg} / \mathrm{kg}$ or saline $)$. D DHEA levels in rats grouped by housing ( $\mathrm{NaEn}$ or standard)

differ significantly in rats by play $(F(1,58)=1.57, p=0.21$, $\left.\eta^{2}=0.05\right)$, whereas both icariin $(F(1,58)=31.66, p<0.001$, $\eta^{2}=0.431-$ Fig. 3C) and housing $(F(1,58)=5.42$, $p=0.023, \eta^{2}=0.191-$ Fig. 3D) were related to a significant increase in DHEA levels. A significant interaction effect between time and treatment was also found for both icariin $\left(F(6,348)=7.84, p<0.001, \eta^{2}=0.44-\right.$ Fig. 3 C $)$ and hous ing $\left(F(6,348)=25.66, p<0.001, \eta^{2}=0.206-\right.$ Fig. 3D $)$ : after the first 2 weeks, rats who were administered icariin showed an elevated DHEA level until the FST, while rats housed in the NaEn showed an elevated DHEA profile at the end of the experiment.

\section{Metabolized T levels}

Metabolized T levels changed significantly during the experiment $\left(F(6,354)=77.12, p<0.001, \eta^{2}=0.567\right)$. T increased after exposure to the chronic stress and decreased significantly after the FST (Fig. 4A).

Metabolized $\mathrm{T}$ levels did not change significantly by the treatments $\left(F(5,54)=1.24, p=0.31, \eta^{2}=0.103\right)$, but a significant interaction effect between time and treatment was

found $\left(F(30,324)=4.81, p<0.001, \eta^{2}=0.308\right)$. Rats not exposed to social play and/or icariin, in either housing conditions, had the largest decrease in T after the FST (Fig. 4B). Analysis of the individual main effect for each treatment condition revealed that $\mathrm{T}$ did not differ significantly in rats by play $\left(F(1,58)=0.88, p=0.20, \eta^{2}=0.007\right)$ and by housing $\left(F(1,58)=0.98, p=0.76 ; \eta^{2}=0.011\right)$, but icariin had a significant effect on $\mathrm{T}(F(1,58)=4.58, p=0.031$, $\eta^{2}=0.101-$ Fig. 4C). A significant interaction effect between time and treatment was also found for both icariin $\left(F(6,348)=13.27, p<0.001, \eta^{2}=0.197-\right.$ Fig. $\left.4 C\right)$ and housing $\left(F(6,348)=5.36, p=0.001, \eta^{2}=0.098-\right.$ Fig. $\left.4 \mathrm{D}\right)$ : icariin was related to T levels after the FST (Fig. 4C), while enriched housing condition ( $\mathrm{NaEn}$ ) tended to increase T over time and after the FST as well (Fig. 4D).

\section{Forced Swim Task}

During the FST, dives were negatively correlated with CORT levels $(r=-0.356, p=0.005)$ and positively correlated with T levels $(r=0.353, p=0.006)$. Shakes showed a 


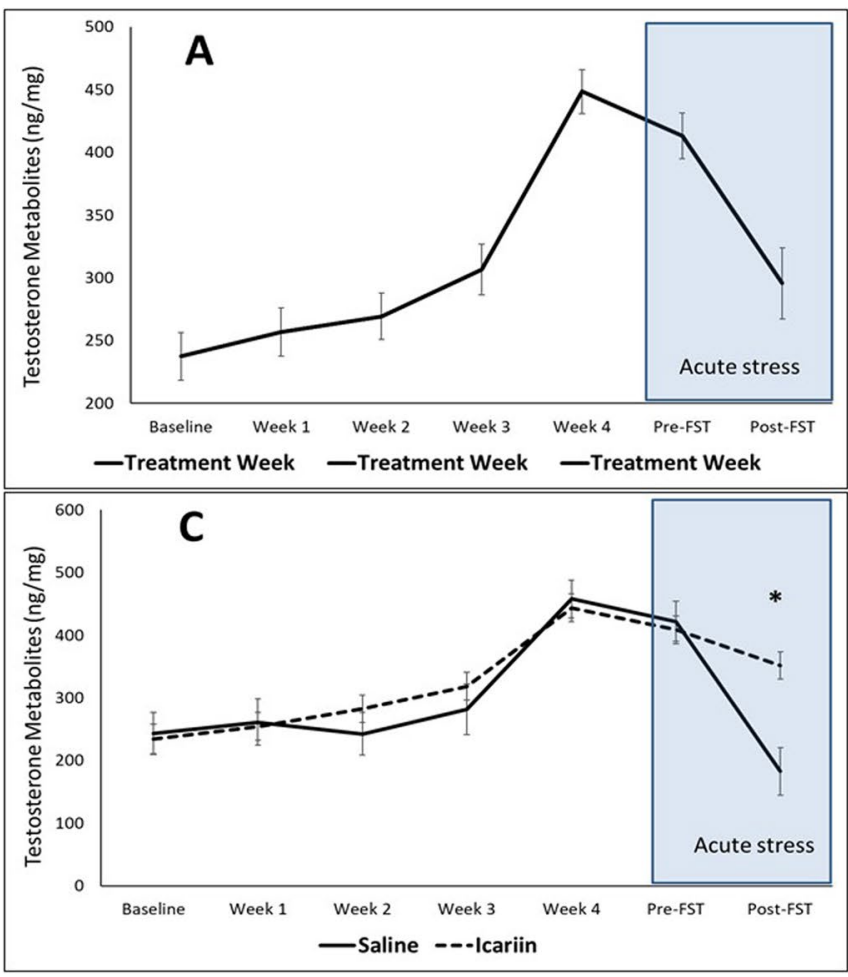

Fig. 4 Metabolized $\mathrm{T}$ levels (ng/mg \pm 2 SEM) during the exposure to unpredictable stress (weeks 1 through 4), and before and after the Forced Swim Task (FST). A Average T levels for all rats. B DHEA levels by group. SS, control rats (standard housing and saline); SI, standard housing and icariin; SIP, standard housing, icariin, and play;

positive correlation with CORT $(r=0.345, p=0.007)$. Floating time was not associated with hormones during the FST (all $p>0.08$ ).

Housing and icariin showed a significant effect on the behavioral output during the FST. Animals in the NaEn condition dove more $(F(1,54)=9.18, p=0.004)$ and shook less $(F(1,54)=34.7, p<0.001)$ during the FST (Fig. 5A). Animals receiving icariin dove more $(F(1,54)=22.5, p<0.001)$ and also shook more $(F(1,54)=4.72, p=0.034)$ during the FST (Fig. 5B). Novel play did not have a significant effect on behavior (all $p$-values $>0.51$ ).

\section{Integrative multivariate models}

To evaluate the overall, independent effects of the treatments (icariin/ $\mathrm{NaEn} / \mathrm{play}$ ) on the endocrine profile of rats after chronic stress and in response to an acute stressor (FST), we ran a series of models using a stepwise discriminant analysis (DA). The treatment served as the grouping variable, and the difference in endocrine levels between the baseline and at the end of the chronic stress for each hormone, as well as the
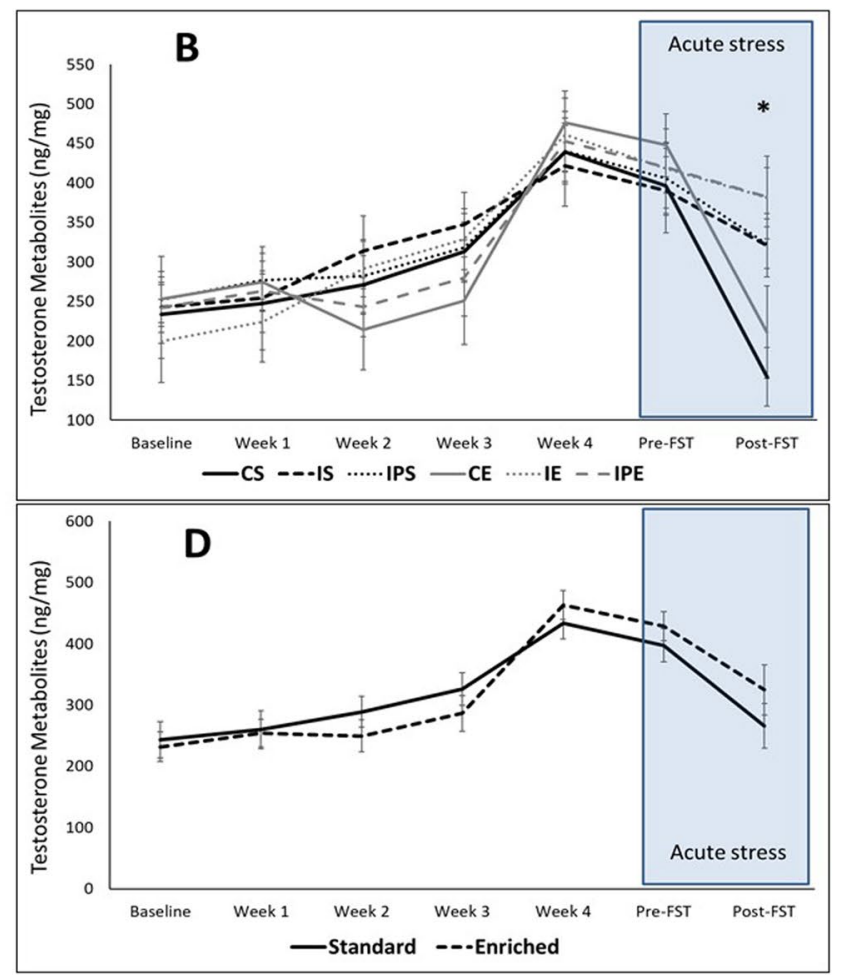

ES, enriched housing and saline; EI, enriched housing and icariin; EIP, enriched housing, icariin, and play. $\mathbf{C} \mathrm{T}$ levels in rats grouped by icariin treatment $(80 \mathrm{mg} / \mathrm{kg}$ or saline). (D) $\mathrm{T}$ levels in rats grouped by housing ( $\mathrm{NaEn}$ or standard)

difference between the pre- and post-FST for each hormone, as the independent variables.

Icariin administration provided the best fit, with a prediction accuracy of $96.7 \%$ (Wilk's $\lambda(2,57)=141.2, p<0.001-$ Fig. 6A). Two variables were retained in the model, the difference in the pre- and post-FST for metabolized DHEA and $\mathrm{T}$ levels. Housing provided the next best fit, with an accuracy of $73.3 \%$ (Wilk's $\lambda(1,58)=41.3, p<0.001-$ Fig. $6 \mathrm{~B}$ ). In this model, the only variable retained was the difference in metabolized CORT between the baseline and at the end of the 4 weeks of chronic stress. The least accurate model was based on play $(65.0 \%-$ Wilk's $\lambda(1,58)=15.6, p<0.001-$ Fig. 6C). This model retained the difference in metabolized DHEA levels pre- and post-FST.

\section{Discussion}

The importance of integrative biobehavioral responses to complex challenges, such as prolonged unpredictable stress, is often overlooked by the emphasis on the molecular mechanisms of action (Walker et al., 2017). Nevertheless, organisms adapt to critical circumstances by evoking 
A

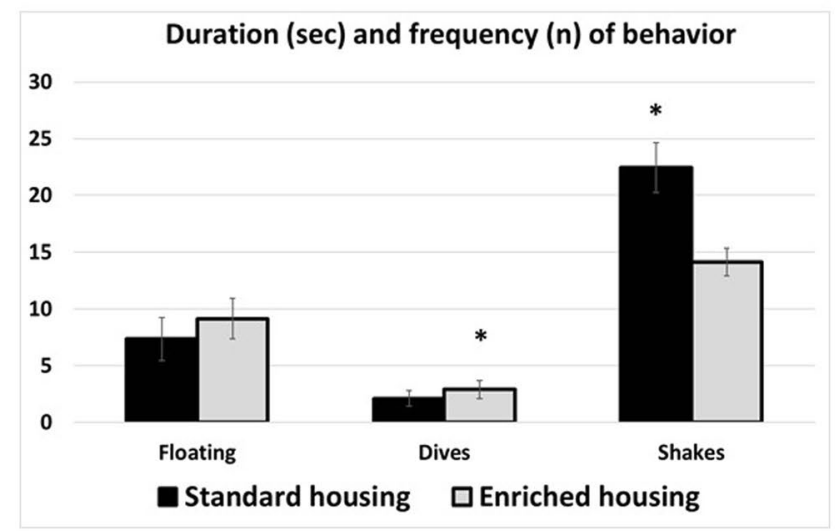

Fig. 5 Differences in the behavioral output during the Forced Swim Task (FST) by treatment. Floating was measured in seconds and dives and shakes in frequency. (A) Number of dives were significantly higher and number of shakes were significantly lower in rats living

multifaceted resilience responses (Lambert et al., 2020). When experienced during early life, these responses can influence brain and body physiology for the entire life span (McEwen, 2008). The main purpose of the current study was to assess the effectiveness of a combination of natural treatments, namely administration of a plant extract known for its anxiolytic properties (Liu et al., 2015; Zheng et al., 2019 ) in conjunction with natural environmental enrichments, often associated with increased resiliency (Bardi et al., 2016; Lambert et al., 2016). Additional social stimulation was also provided in the form of play behavior with an unfamiliar animal. Adolescent rats were selected to increase the probability of long-lasting effects. It was hypothesized that all treatments would be effective in reducing the negative behavioral and physiological responses to unpredictable stress in Long-Evans rats, and that their synergetic effect would increase adaptive responses even further. Our results partially confirmed these hypotheses, indicating that using multiple channels to stimulate adaptive responses can be effective in increasing the ability of an organism to face uncertainty. Considering how quickly our life can change due to unpredictable events (Spinelli and Pellino, 2020), our data is instrumental to a better comprehension of the many aspects of integrative biobehavioral responses.

Icariin had a significant effect on both CORT and DHEA in rats exposed to unpredictable stress and on the behavioral output during the FST as well. The effects on CORT were confined to the acute challenge (FST) after the 4 weeks of chronic stress, when rats given icariin showed a reduction in the amount of physiological stress caused by the forced swim. The effects of DHEA started to manifest during the second week of treatment, when icariin administration
B

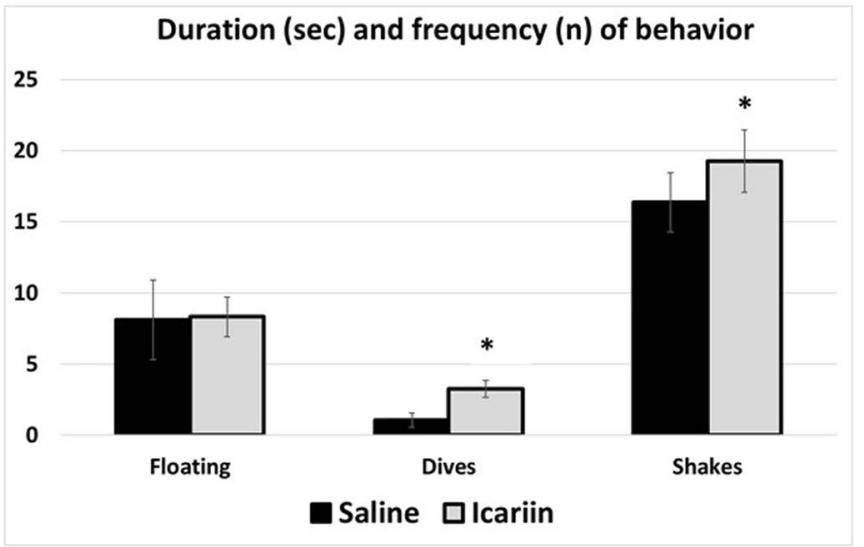

in natural enriched housing in comparison to rats in standard housing. (B) Both number of dives and shakes were significantly higher in rats that were given icariin

was related to a significant increase, more than twofold, in DHEA. The hormone DHEA remained elevated until the end of the experiment, and more importantly, after the FST. Considering previous studies indicated that higher DHEA/ CORT ratios are associated with mental health and resilience (Charney, 2004; Markopoulou et al., 2009; Bardi et al., 2012, 2013), our data showed that icariin could be effective in increasing emotional resilience by increasing the DHEA/ CORT ratio in rats exposed to unpredictable stress. The HPA activity in response to stress is an extraordinarily complex, layered biological adaptation that goes beyond what a single marker can tell us (McEwen, 2018), and therefore we need to be cautious with the interpretation of our data. It is known, for example, that CORT alone cannot indicate if the rats' response is adaptive (generally defined as "good stress") or maladaptive ("bad stress") (Aschbacher et al., 2013). Therefore, in the effort to improve our ability to detect functional changes related to environmental stimuli, several authors have recommended the utility of exploring proportions, as opposed to individual values, of interconnected biological responses to specific systems, such as the HPA axis (Dhabhar, 2014; McEwen, 2018; Lambert et al., 2020; Scarola and Bardi, 2020). Although in this study we did not investigate the mechanism of actions able to explain this relationship, thus limiting considerably our ability to further speculate, previous works have revealed that DHEA can enhance neuroprotection by decreasing glucocorticoidinduced apoptosis in various key brain areas, including the amygdala and hippocampus, and to promoting neurogenesis in the dentate gyrus (Maninger et al., 2009; Morgan et al., 2009; Goncharova et al., 2012). Therefore, these mechanisms could be the basis of the enhanced negative feedback 
A

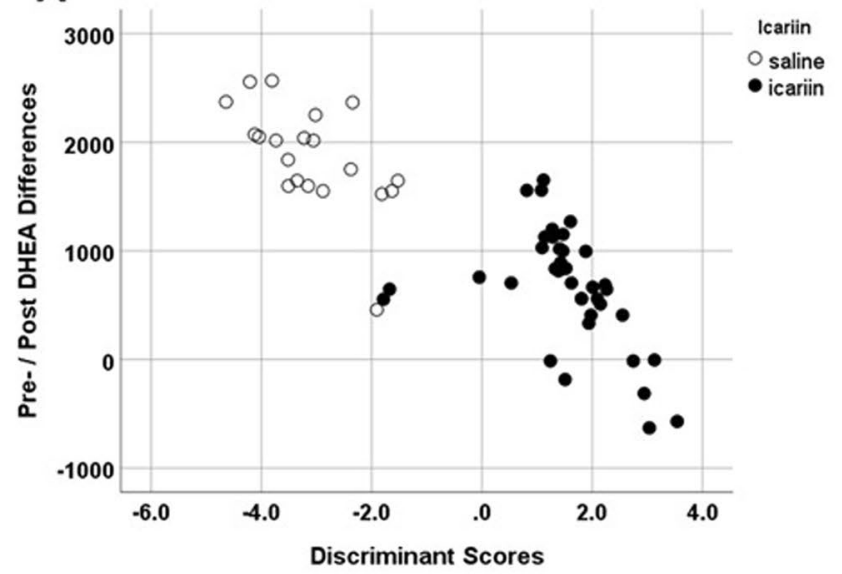

C

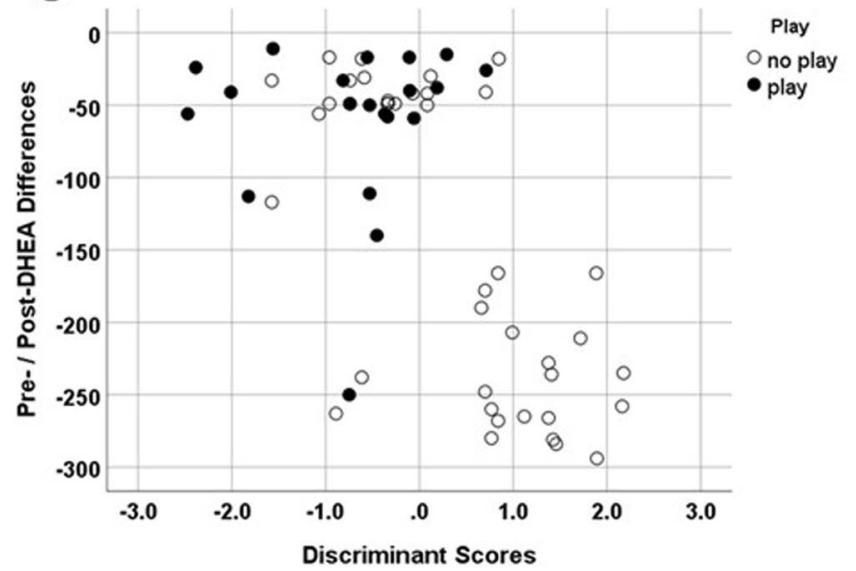

Fig. 6 Discriminant analysis (DA) models of the integrative relationship between endocrine levels and treatments. Discriminant scores are plotted against the values of the variable with the highest contribution to the model. A For icariin, the best fit retained the DHEA difference before and after the FST (96\% accuracy). B For housing, the

system regulating neurochemical and cognitive reappraisal of stressful events observed in rats after icariin administration. Further studies specifically designed to test these mechanisms are needed to test this hypothesis.

To verify if these effects were confined to the neurobiological system directly involved in the stress response (the HPA axis) or if they could be part of a larger integrative response among multiple, interrelated systems, the HPG axis activity was also assessed by measuring $\mathrm{T}$ levels. It was found that metabolized $\mathrm{T}$ levels were also affected by icariin treatment; specifically, it was associated with higher $\mathrm{T}$ after the FST, thus showing that the icariin can protect against naturally occurring reduction in $\mathrm{T}$ usually observed in animals under stress (Retana-Marquez et al., 2003). This is not surprising, since icariin has been identified as a testosterone enhancer (Zhang and Yang, 2006). In their study, Zhang and Yang found that prolonged treatment of
B

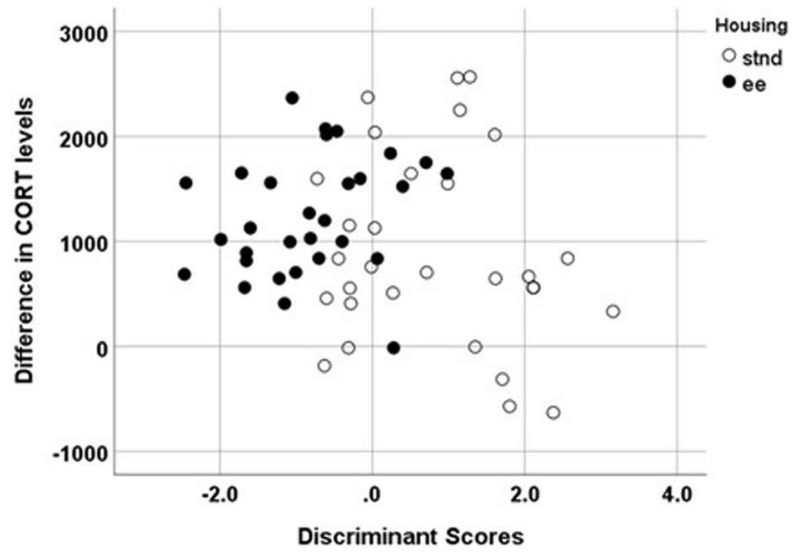

best fit retained the difference in CORT levels between the baseline and at the end of the 4 weeks of chronic unpredictable stress $(96 \%$ accuracy). C For social play, the best model retained the DHEA difference before and after the FST (66\% accuracy)

hypoandrogenic male rats with icariin improved the condition of reproductive organs and increased the circulating level of testosterone, thus indicating that icariin can upregulate HPG activity (Zhang and Yang, 2006). Moreover, sex steroids have been found to exhibit anxiolytic- and antidepressant-like effects in gonadectomized male rats, via a central mechanism involving $\mathrm{T}$ aromatization in the dentate gyrus (Carrier et al., 2015). Our results confirm that icariin can help in $\mathrm{T}$ production during stressful events in intact males as well. Alternatively, icariin could act on the metabolic relationship between DHEA and T (Prough et al., 2016; Smith et al., 2019), thus creating an indirect effect on emotional resilience. It is well known that circulating DHEA is converted to testosterone or estrogen in the target tissues (Baulieu, 1996). Furthermore, testosterone is converted to $5 \alpha$-dihydrotestosterone (DHT) by $5 \alpha$-reductase and exerts biophysiological actions through binding to androgen 
receptors (Celotti et al., 1991). However, it remains unclear whether different areas can synthesize DHT from testosterone and/or DHEA, and whether these hormones affect glucose metabolism-related signaling pathways, and thus further studies are necessary to disentangle this issue.

Enriching the rats' environment ( $\mathrm{NaEn}$ ) also had a significant effect on both CORT and DHEA. An enriched environment helped to lower the CORT response of rats throughout the 4 weeks of unpredictable stress and after the FST, while DHEA production was enhanced. Once again, these results pointed toward an increased DHEA/CORT ratio and, ultimately, improved emotional regulation, confirming the findings of previous studies (Bardi et al., 2016; Lambert et al., 2016). In contrast to the icariin effects, NaEn did not influence $\mathrm{T}$ directly. This result was unexpected since previous studies have found a significant association between environmental enrichment and T levels (Avital et al., 2011; Mitra and Sapolsky, 2012). One possible explanation is that the effects of NaEn on $\mathrm{T}$ could manifest later during adulthood in male rats, whereas our rats were still relatively young. Nevertheless, NaEn proved once more to enhance neuroprotection against unpredictable stress. Even more importantly, the synergetic effect of icariin and $\mathrm{NaEn}$ treatments was found to have a stronger effect on all neuroendocrine markers and their ratios. These findings, if confirmed with human data, might have profound implications on how we shape policies to promote healthy life choices. Although we need to resist the temptation to data over-interpretation, rapidly increasing levels of stress, socio-economic disparity, and biological and environmental global threats such as COVID-19 and climate changes are all exerting a significant toll on human physical and mental health, and thus we need urgent solutions. In parallel with finding better ways to deal with each of these specific issues, it is also imperative to promote holistic and widely accessible methods of increasing emotional resilience. For example, medical students experiencing high level of stress showed impaired functional connectivity in fMRI scans involving several limbic areas and the pre-frontal cortex; however, just 1 month of vacation was enough to reverse most of these neurological damages (Liston et al., 2009). In animal models, even moderate and discontinuous exposure to enrichment and other mitigating factors such as contingency learning in during early life were enough to provide benefits in stress reduction, aging, and immune activation throughout the life span (Scarola et al., 2019; Scarola and Bardi, 2020). Our results indicate that any positive intervention during early life can have significant effects on adaptive mechanism of emotional regulation.

Novel social positive interactions with other rats did not appear to be significantly related to the endocrine profile during chronic stress and during following acute challenges (FST). This result was also surprising, since many studies have found that social play can significantly reduce stress and increase emotional regulation in both humans (Galyer and Evans, 2001) and non-human animals (Pellis et al., 2010). The method and timing of which social play interactions were conducted most likely influenced this result. In the future, a study planned on social interactions alone is planned. The biggest limitation of our study was that rats could still properly interact with a familiar peer in the home environment, thus potentially masking the effects of the 5 min of interactions with a different animal. Furthermore, the effects of social play could have been washed out by the more pronounced effects of icariin and NaEn. When we attempted to disentangle these effects by assessing the synergetic effects of play with both icariin and $\mathrm{NaEn}$, it was found that the group that received all three treatments did as well as the group just treated with icariin and NaEn. Further studies focusing on play behavior in different settings and with a larger number of rats would be needed to estimate the independent contribution of play on emotional regulation.

Multiple models were created to assess the effects of all three treatments on changing endocrine levels during the experiment. The goal of these models was to categorize individual rats based on treatments (saline vs. icariin; standard housing vs. NaEn; no play vs. play). Discriminant scores were plotted against the most influential variable in the model. These plots were instrumental in interpreting the relative efficacy of the treatments. Data showed that the most effective treatment was icariin when plotted against DHEA levels before and after the FST. This result confirmed the value of icariin in enhancing DHEA levels during challenging events. The second most effective treatment was NaEn; in a model retaining CORT endocrine levels during the exposure to chronic stress as the most influential variable. This result led to the interpretation that NaEn is particularly important in reducing the negative effects of prolonged stress, as found previously (Bardi et al., 2016; Lambert et al., 2016). Clearly, more studies are needed to confirm this interpretation, including assessing the differential role of icariin on males and females. It was also confirmed that the data collected on play was not enough to accurately categorize individuals within the model, corroborating the results of the GLM analyses. The synergetic effect of icariin and NaEn could be the result of two distinct pathways of action: icariin specifically increasing DHEA levels, and $\mathrm{NaEn}$ decreasing CORT levels. Further studies to investigate the mechanisms of these possible pathways are needed.

\section{Conclusion}

Overall, our data showed promising preliminary evidence that the combination of herbal treatments (icariin) and living in an enriched natural environment (NaEn) can effectively promote emotional resilience in adolescent rats. Current 
evidence from the literature that icariin contains active ingredients that can have anti-oxidative and anti-inflammatory properties that can ameliorate several conditions, from depression to cancer (Liu et al., 2015; Tan et al., 2016). Our data confirmed that icariin can contribute to the regulation and balance of endocrine activity of animals under stress. Several more questions remain to be addressed. For example, are these effects far-reaching and can extend throughout the rats' lives or are they short lived? Can similar effects be verified in female rats? What are the specific neural mechanisms of action responsible for the increased emotional regulation due to icariin and NaEn? Can icariin and $\mathrm{NaEn}$ also interact to mediate essential functions such as the immune system, inflammation, and aging? How well can these results be translated to humans, especially when we focus on populations living in an impoverished area? Our model offers new avenues to determine how we can go back to more natural treatments as an alternative to more aggressive pharmacological treatments for affective disorders, such as anxiety and depression, in a time in which social, biological, and environmental challenges have effectively become the new norm.

Acknowledgements Our thanks and deep appreciation to Kayla Johnson for her vital pilot work on icariin dosages and route of administration for Long-Evans rats. Many thanks to Alex Chapman and Hailey Donald for their invaluable help in the preparation of this manuscript.

Funding This project was supported by the Randolph-Macon College (R-MC) Department of Psychology and Neuroscience, the R-MC Shapiro Undergraduate Research Fellowship, and the R-MC Chenery Grant to MB.

\section{References}

Aschbacher K, O’Donovan A, Wolkowitz OM, Dhabhar FS, Su Y, Epel E (2013) Good stress, bad stress and oxidative stress: insights from anticipatory cortisol reactivity. Psychoneuroendocrino 38:1698-1708. https://doi.org/10.1016/j.psyneuen.2013.02.004

Ashokan A, Hegde A, Balasingham A, Mitra R (2018) Housing environment influences stress-related hippocampal substrates and depression-like behavior. Brain Res 1683:78-85. https://doi.org/ 10.1016/j.brainres.2018.01.021

Avital A, Dolev T, Aga-Mizrachi S, Zubedat S (2011) Environmental enrichment preceding early adulthood methylphenidate treatment leads to long term increase of corticosterone and testosterone in the rat. PLoS ONE 6:e22059. https://doi.org/10.1371/journal. pone.0022059

Bardi M, Hampton JE, Lambert KG (2010) Fecal dehydroepiandrosterone (DHEA) immunoreactivity as a noninvasive index of circulating DHEA activity in young male laboratory rats. Comp Med 60(6):455-460

Bardi, M., Kaufman, C., Franssen, C., Hyer, M. M., Rzucidlo, A., Brown, M., Tschirhart, M., Lambert, K. G., 2016. Paper or plastic? Exploring the effects of natural enrichment on behavioural and neuroendocrine responses in Long-Evans rats. J Neuroendocrinol. 28. https://doi.org/10.1111/jne.12383
Bardi M, Rhone AP, Franssen CL, Hampton JE, Shea EA, Hyer MM, Huber J, Lambert KG (2012) Behavioral training and predisposed coping strategies interact to influence resilience in male Long-Evans rats: implications for depression. Stress 15:306-317. https://doi.org/10.3109/10253890.2011.623739

Bardi M, True M, Franssen CL, Kaufman C, Rzucidlo A, Lambert KG (2013) Effort-based reward (EBR) training enhances neurobiological efficiency in a problem-solving task: insights for depression therapies. Brain Res 1490:101-110. https://doi.org/10.1016/j. brainres.2012.10.027

Baulieu EE (1996) Dehydroepiandrosterone (DHEA): a fountain of youth? J Clin Endocr Metab 81:3147-3151. https://doi.org/10. 1210/jcem.81.9.8784058

Benedetti F, Carlino E, Pollo A (2011) How placebos change the patient's brain. Neuropsychopharmacol 36:339-354. https://doi. org/10.1038/npp.2010.81

Carrier N, Saland SK, Duclot F, He H, Mercer R, Kabbaj M (2015) The anxiolytic and antidepressant-like effects of testosterone and estrogen in gonadectomized male rats. Biol Psychiat 78:259-269. https://doi.org/10.1016/j.biopsych.2014.12.024

Cascade E, Kalali AH, Kennedy SH (2009) Real-world data on SSRI antidepressant side effects. Psychiatr 6:16-18

Celotti F, Melcangi RC, Negri-Cesi P, Poletti A (1991) Testosterone metabolism in brain cells and membranes. J Steroid Biochem 40:673-678. https://doi.org/10.1016/0960-0760(91)90289-H

Charmandari E, Tsigos C, Chrousos G (2005) Endocrinology of the stress response. Annu Rev Physiol 67:259-284. https://doi.org/ 10.1146/annurev.physiol.67.040403.120816

Charney DS (2004) Psychobiological mechanisms of resilience and vulnerability: implications for successful adaptation to extreme stress. Am J Psychiat 161:195-216. https://doi.org/10.1176/appi. ajp.161.2.195

Dallman MF, Akana SF, Bradbury MJ, Strack AM, Hanson ES, Scribner KA (1994) Regulation of the hypothalamo-pituitary-adrenal axis during stress: feedback, facilitation and feeding. Semin Neurol 6(4):205-213. https://doi.org/10.1006/smns.1994.1027

Dhabhar FS (2014) Effects of stress on immune function: the good, the bad, and the beautiful. Immunol Res 58:193-210. https://doi.org/ 10.1007/s12026-014-8517-0

Enck P, Benedetti F, Schedlowski M (2008) New insights into the placebo and nocebo responses. Neuron 59:195-206. https://doi.org/ 10.1016/j.neuron.2008.06.030

Fagundes CP, Glaser R, Kiecolt-Glaser JK (2013) Stressful early life experiences and immune dysregulation across the lifespan. Brain Behav Immun 27:8-12. https://doi.org/10.1016/j.bbi.2012.06.014

Frumkin H, Bratman GN, Breslow SJ, Cochran B, Kahn PH Jr, Lawler JJ, Levin PS, Tandon PS, Varanasi U, Wolf KL, Wood SA (2017) Nature contact and human health: a research agenda. Environ Health Persp 125:075001. https://doi.org/10.1289/EHP1663

Galyer KT, Evans IM (2001) Pretend play and the development of emotion regulation in preschool children. Early Child Dev Care 166:93-108. https://doi.org/10.1080/0300443011660108

Goncharova ND, Vengerin AA, Chigarova OA (2012) Repeated moderate stress stimulates the production of dehydroepiandrosterone sulfate (DHEAS) and reduces corticosteroid imbalance in old Macaca mulatta. B Exp Biol Med+ 153:750-753. https://doi.org/ 10.1007/s10517-012-1817-2

Gong M, Han B, Wang S, Liang S, Zou Z (2016) Icariin reverses corticosterone-induced depression-like behavior, decrease in hippocampal brain-derived neurotrophic factor (BDNF) and metabolic network disturbances revealed by NMR-based metabonomics in rats. J Pharmaceut Biomed 123:63-73. https://doi.org/10. 1016/j.jpba.2016.02.001

He C, Wang Z, Shi J (2020) Pharmacological effects of icariin. Adv Pharmacol 87:179-203. https://doi.org/10.1016/bs.apha.2019.10.004 
Hritcu L, Ionita R, Postu PA, Gupta GK, Turkez H, Lima TC, Carvalho CUS, de Sousa DP (2017) Antidepressant flavonoids and their relationship with oxidative stress. Oxid Med Cell Longev 2017:1-18. https://doi.org/10.1155/2017/5762172

Johnson K (2019) Back to nature: herbal treatment can increase emotional resilience in Long-Evans rat males exposed to chronic unpredictable stress. Senior Thesis, Randolph-Macon College, Ashland, VA

Khan M, Maryam A, Qazi JI, Ma T (2015) Targeting apoptosis and multiple signaling pathways with icariside II in cancer cells. Int J Biol Sci 11(9):1100-1112. https://doi.org/10.7150/ijbs.11595

Kinrys G, Coleman E, Rothstein E (2009) Natural remedies for anxiety disorders: potential use and clinical applications. Depress Anxiety 26:259-265. https://doi.org/10.1002/da.20460

Lakhan SE, Vieira KF (2010) Nutritional and herbal supplements for anxiety and anxiety-related disorders: systematic review. Nutr J 9:42. https://doi.org/10.1186/1475-2891-9-42

Lambert KG, Hyer MM, Rzucidlo AA, Bergeron T, Landis T, Bardi M 2014 Contingency-based emotional resilience: effort-based reward training and flexible coping lead to adaptive responses to uncertainty in male rats. Front Behav Neurosci. 8. https://doi. org/10.3389/fnbeh.2014.00124

Lambert K, Hunter RG, Bartlett AA, Lapp HE, Kent M (2020) In search of optimal resilience ratios: differential influences of neurobehavioral factors contributing to stress-resilience spectra. Front Neuroendocrin 56:100802. https://doi.org/10.1016/j. yfrne.2019.100802

Lambert K, Hyer M, Bardi M, Rzucidlo A, Scott S, Terhune-cotter B, Hazelgrove A, Silva I, Kinsley C (2016) Natural-enriched environments lead to enhanced environmental engagement and altered neurobiological resilience. Neuroscience 330:386-394. https://doi.org/10.1016/j.neuroscience.2016.05.037

Lee SH, Paz-Filho G, Mastronardi C, Licinio J, Wong M-L (2016) Is increased antidepressant exposure a contributory factor to the obesity pandemic? Transl Psychiat 6:e759-e759. https://doi.org/ 10.1038/tp.2016.25

Li C, Li Q, Mei Q, Lu T (2015) Pharmacological effects and pharmacokinetic properties of icariin, the major bioactive component in Herba Epimedii. Life Sci 126:57-68. https://doi.org/10.1016/j. 1fs.2015.01.006

Li L, Wang XM (2008) Progress of pharmacological research on icariin. Zhongguo Zhong Yao Za Zhi 33:2727-2732

Liston C, McEwen BS, Casey BJ (2009) Psychosocial stress reversibly disrupts prefrontal processing and attentional control. P Natl Acad Sci 106:912-917. https://doi.org/10.1073/pnas.0807041106

Liu B, Xu C, Wu X, Liu F, Du Y, Sun J, Tao J, Dong J (2015) Icariin exerts an antidepressant effect in an unpredictable chronic mild stress model of depression in rats and is associated with the regulation of hippocampal neuroinflammation. Neuroscience 294:193205. https://doi.org/10.1016/j.neuroscience.2015.02.053

Ma H, He X, Yang Y, Li M, Hao D, Jia Z (2011) The genus Epimedium: an ethnopharmacological and phytochemical review. J Ethnopharmacol 134:519-541. https://doi.org/10.1016/j.jep.2011. 01.001

Maninger N, Wolkowitz OM, Reus VI, Epel ES, Mellon SH (2009) Neurobiological and neuropsychiatric effects of dehydroepiandrosterone (DHEA) and DHEA sulfate (DHEAS). Front Neuroendocrin 30:65-91. https://doi.org/10.1016/j.yfrne.2008.11.002

Markopoulou K, Papadopoulos A, Juruena MF, Poon L, Pariante CM, Cleare AJ (2009) The ratio of cortisol/DHEA in treatment resistant depression. Psychoneuroendocrino 34:19-26. https://doi.org/ 10.1016/j.psyneuen.2008.08.004

Martin LJ, Hathaway G, Isbester K, Mirali S, Acland EL, Niederstrasser N, Slepian PM, Trost Z, Bartz JA, Sapolsky RM, Sternberg WF, Levitin DJ, Mogil JS (2015) Reducing social stress elicits emotional contagion of pain in mouse and human strangers. Curr Biol 25:326-332. https:// doi.org/10.1016/j.cub.2014.11.028

Maust DT, Blow FC, Wiechers IR, Kales HC, Marcus SC (2017) National trends in antidepressant, benzodiazepine, and other sedative-hypnotic treatment of older adults in psychiatric and primary care. J Clin Psychiat 78:e363-e371. https://doi.org/10. 4088/JCP.16m10713

McEwen BS (2008) Understanding the potency of stressful early life experiences on brain and body function. Metabolism 57:S11-S15. https://doi.org/10.1016/j.metabol.2008.07.006

McEwen BS (2018) Redefining neuroendocrinology: epigenetics of brain-body communication over the life course. Front Neuroendocrin 49:8-30. https://doi.org/10.1016/j.yfrne.2017.11.001

McQuade JL, Meng Z, Chen Z, Wei Q, Zhang Y, Bei W, Palmer JL, Cohen L (2012) Utilization of and attitudes towards traditional Chinese medicine therapies in a Chinese cancer hospital: a survey of patients and physicians. Evid-Based Compl Alt 2012:1-11. https://doi.org/10.1155/2012/504507

Mitchell R, Popham F (2008) Effect of exposure to natural environment on health inequalities: an observational population study. The Lancet 372:1655-1660. https://doi.org/10.1016/S0140-6736(08) 61689-X

Mitra R, Sapolsky RM (2012) Short-term enrichment makes male rats more attractive, more defensive and alters hypothalamic neurons. PLoS ONE 7:e36092. https://doi.org/10.1371/journal.pone.00360 92

Morgan CA, Rasmusson A, Pietrzak RH, Coric V, Southwick SM (2009) Relationships among plasma dehydroepiandrosterone and dehydroepiandrosterone sulfate, cortisol, symptoms of dissociation, and objective performance in humans exposed to underwater navigation stress. Biol Psychiat 66:334-340. https://doi.org/10. 1016/j.biopsych.2009.04.004

Nithianantharajah J, Hannan AJ (2006) Enriched environments, experience-dependent plasticity and disorders of the nervous system. Nat Rev Neurosci 7:697-709. https://doi.org/10.1038/nrn1970

Olfson M, Marcus SC (2009) National patterns in antidepressant medication treatment. Arch Gen Psychiat 66:848. https://doi.org/10. 1001/archgenpsychiatry.2009.81

Pan Y, Hong Y, Zhang Q-Y, Kong L-D (2013) Impaired hypothalamic insulin signaling in CUMS rats: restored by icariin and fluoxetine through inhibiting CRF system. Psychoneuroendocrino 38:122134. https://doi.org/10.1016/j.psyneuen.2012.05.007

Pan Y, Kong L-D, Li Y-C, Xia X, Kung H-F, Jiang F-X (2007) Icariin from Epimedium brevicornum attenuates chronic mild stressinduced behavioral and neuroendocrinological alterations in male Wistar rats. Pharmacol Biochem Be 87:130-140. https://doi.org/ 10.1016/j.pbb.2007.04.009

Park BJ, Tsunetsugu Y, Kasetani T, Kagawa T, Miyazaki Y (2010) The physiological effects of Shinrin-yoku (taking in the forest atmosphere or forest bathing): evidence from field experiments in 24 forests across Japan. Environ Health and Prev 15:18-26. https://doi.org/10.1007/s12199-009-0086-9

Pellis SM, Pellis VC (2007) Rough-and-tumble play and the development of the social brain. Curr Dir Psychol Sci 16:95-98. https:// doi.org/10.1111/j.1467-8721.2007.00483.x

Pellis SM, Pellis VC, Bell HC (2010) The function of play in the development of the social brain. Am J Play 2:278-296

Prough RA, Clark BJ, Klinge CM (2016) Novel mechanisms for DHEA action. J Mol Endocrinol 56:R139-R155. https://doi.org/10.1530/ JME-16-0013

Rehan W, Antfolk J, Johansson A, Jern P, Santtila P (2017) Experiences of severe childhood maltreatment, depression, anxiety and alcohol abuse among adults in Finland. PLoS ONE 12:e0177252. https:// doi.org/10.1371/journal.pone.0177252

Retana-Márquez S, Bonilla-Jaime H, Vázquez-Palacios G, MartínezGarcía R, Velázquez-Moctezuma J (2003) Changes in masculine 
sexual behavior, corticosterone and testosterone in response to acute and chronic stress in male rats. Horm Behav 44:327-337. https://doi.org/10.1016/j.yhbeh.2003.04.001

Rook GA (2013) Regulation of the immune system by biodiversity from the natural environment: an ecosystem service essential to health. P Natl Acad Sci 110:18360-18367. https://doi.org/10. 1073/pnas. 1313731110

Scarola, S. J., Bardi, M., 2020. Environmental enrichment modulates inflammation during development in Long-Evans rats (Rattus norvegicus). Dev Psychobiol. dev.22007. https://doi.org/10.1002/dev. 22007

Scarola S, Kent M, Neal S, Trejo JP, Bardi M, Lambert K (2020) Postpartum environmental challenges alter maternal responsiveness and offspring development. Horm Behav 122:104761

Scarola SJ, Perdomo Trejo JR, Granger ME, Gerecke KM, Bardi M (2019) Immunomodulatory effects of stress and environmental enrichment in Long-Evans rats (Rattus norvegicus). Comparative Med. 69, 35-47. https://doi.org/10.30802/ AALAS-CM-18-000025

Smith JD, Johnson KA, Whittle S, Allen NB, Simmons JG (2019) Measurement of cortisol, dehydroepiandrosterone, and testosterone in the hair of children: preliminary results and promising indications. Dev Psychobiol 61:962-970. https://doi.org/10.1002/ dev. 21807

Spinelli A, Pellino G (2020) COVID-19 pandemic: perspectives on an unfolding crisis. Brit J Surg 107:785-787. https://doi.org/10. 1002/bjs. 11627

Sun S, Liu L, Tian X, Guo Y, Cao Y, Mei Y, Wang C (2019) Icariin attenuates high glucose-induced apoptosis, oxidative stress, and inflammation in human umbilical venous endothelial cells. Planta Med 85:473-482. https://doi.org/10.1055/a-0837-0975

Tafet GE, Nemeroff CB (2016) The links between stress and depression: psychoneuroendocrinological, genetic, and environmental interactions. J Neuropsych Clin n 28:77-88. https://doi.org/10. 1176/appi.neuropsych.15030053

Tan HL, Chan KG, Pusparajah P, Saokaew S, Duangjai A, Lee LH, Goh BH (2016) Anti-cancer properties of the naturally occurring aphrodisiacs: icariin and its derivatives. Front Pharmacol 7:191

Ulrich R (1984) View through a window may influence recovery from surgery. Science 224:420-421. https://doi.org/10.1126/science. 6143402
Vanderschuren LJMJ, Achterberg EJM, Trezza V (2016) The neurobiology of social play and its rewarding value in rats. Neurosci Biobehav R 70:86-105. https://doi.org/10.1016/j.neubiorev.2016. 07.025

Vega-Rivera NM, Ortiz-López L, Gómez-Sánchez A, Oikawa-Sala J, Estrada-Camarena EM, Ramírez-Rodríguez GB (2016) The neurogenic effects of an enriched environment and its protection against the behavioral consequences of chronic mild stress persistent after enrichment cessation in six-month-old female Balb/C mice. Behav Brain Res 301:72-83. https://doi.org/10.1016/j.bbr. 2015.12.028

Walker C-D, Bath KG, Joels M, Korosi A, Larauche M, Lucassen PJ, Morris MJ, Raineki C, Roth TL, Sullivan RM, Taché Y, Baram TZ (2017) Chronic early life stress induced by limited bedding and nesting (LBN) material in rodents: critical considerations of methodology, outcomes and translational potential. Stress 20:421-448. https://doi.org/10.1080/10253890.2017.1343296

Wei K, Xu Y, Zhao Z, Wu X, Du Y, Sun J, Yi T, Dong J, Liu B (2016) Icariin alters the expression of glucocorticoid receptor, FKBP5 and SGK1 in rat brains following exposure to chronic mild stress. International J Mol Med 38:337-344. https://doi.org/10.3892/ ijmm.2016.2591

Xu W, Zhang Y, Yang M, Shen Z, Zhang X, Zhang W et al (2007) LC-MS/MS method for the simultaneous determination of icariin and its major metabolites in rat plasma. J Pharm Biomed Ana 45:667-672. https://doi.org/10.1016/j.jpba.2007.07.007

Zhang Z-B, Yang Q-T (2006) The testosterone mimetic properties of icariin. Asian J Androl 8:601-605. https://doi.org/10.1111/j.17457262.2006.00197.x

Zheng X, xing, Chen, Y. wei, Yue, Y. song, Li, Y. chun, Xia, S. zhe, Li, Y., Deng, H. huan, He, J., Cao, Y. jun., (2019) Icariin ameliorates learning and memory impairments through ERK/CaMKII $\alpha / C R E B$ signaling and HPA axis in prenatally stressed female offspring. Biomed Pharmacother 117:109077. https://doi.org/10.1016/j. biopha.2019.109077

Publisher's note Springer Nature remains neutral with regard to jurisdictional claims in published maps and institutional affiliations. 